\title{
Risk of intracranial hemorrhage after carotid artery stenting versus endarterectomy: a population-based study
}

\author{
${ }^{*}$ Mohamad A. Hussain, MD, PhD,, 1,2 Aziz S. Alali, MD, PhD, $, 3,4$ \\ Muhammad Mamdani, PharmD, MA, MPH, ${ }^{5-9}$ Jack V. Tu, MD, PhD, $, 3,6,8-10$ \\ Gustavo Saposnik, MD, MSc, ${ }^{5,6,8,9,11}$ Konard Salata, MD, ${ }^{1,2}$ Avery B. Nathens, MD, PhD, 2,3,6,8,12 \\ Charles de Mestral, MD, PhD, ${ }^{1,2,5}$ Deepak L. Bhatt, MD, MPH, ${ }^{13}$ Subodh Verma, MD, PhD, ${ }^{2,5,7,14}$ and \\ Mohammed Al-Omran, MD, MSc ${ }^{1,2,5,7,15}$
}

\begin{abstract}
${ }^{1}$ Division of Vascular Surgery, ${ }^{5} \mathrm{Li}$ Ka Shing Knowledge Institute, and Divisions of ${ }^{11}$ Neurology and ${ }^{14}$ Cardiac Surgery, St. Michael's Hospital; ' 2 Department of Surgery, ${ }^{4}$ Interdepartmental Division of Critical Care, and ${ }^{9}$ Department of Medicine, University of Toronto; ${ }^{3}$ Sunnybrook Research Institute, ${ }^{10}$ Division of Cardiology, and ${ }^{12}$ Department of Surgery, Sunnybrook Health Sciences Centre; ${ }^{6}$ Institute of Health Policy, Management, and Evaluation; ${ }^{8}$ Institute for Clinical Evaluative Sciences, Toronto, Ontario, Canada; ${ }^{7}$ King Saud University-Li Ka Shing Collaborative Research Program and ${ }^{15}$ Department of Surgery, King Saud University, Riyadh, Kingdom of Saudi Arabia; and ${ }^{13}$ Brigham and Women's Hospital Heart \& Vascular Center, Harvard Medical School, Boston, Massachusetts
\end{abstract}

OBJECTIVE Intracranial hemorrhage (ICH) associated with cerebral hyperperfusion syndrome is a rare but major complication of carotid artery revascularization. The objective of this study was to compare the rate of ICH after carotid artery stenting (CAS) with that after endarterectomy (CEA).

METHODS The authors performed a retrospective population-based cohort study of patients who underwent carotid artery revascularization in the province of Ontario, Canada, between 2002 and 2015 . The primary outcome was the rate of $\mathrm{ICH}$ that occurred within 90 days after carotid artery intervention among patients who underwent CAS versus that of those who underwent CEA. The authors used inverse probability of treatment weighting and propensity scores to account for selection bias. In sensitivity analyses, patients who had postprocedure ischemic stroke were excluded, and the following subgroups were examined: patients with symptomatic and asymptomatic carotid artery stenosis, patients treated between 2010 and 2015, and patients aged $\geq 66$ years (to account for antiplatelet and anticoagulant use).

RESULTS A total of 16,688 patients underwent carotid artery revascularization (14\% CAS, $86 \%$ CEA). Patients with more comorbid illnesses, symptomatic carotid artery stenosis, or cardiac disease and those who were taking antiplatelet agents or warfarin before surgery were more likely to undergo CAS. Among the overall cohort, $80(0.48 \%)$ patients developed $\mathrm{ICH}$ within 90 days $(0.85 \%$ after CAS, $0.42 \%$ after CEA). The 180 -day mortality rate after $\mathrm{ICH}$ in the overall cohort was $2.7 \%$, whereas the 180-day mortality rate among patients who suffered ICH was $42.5 \%$ (40\% for CAS-treated patients, $43.3 \%$ for CEA-treated patients). In the adjusted analysis, patients who underwent CAS were significantly more likely to have ICH than those who underwent CEA (adjusted OR 1.77; 95\% Cl 1.32-2.36; $p<0.001$ ). These results were consistent after excluding patients who developed postprocedure ischemic stroke (adjusted OR 1.90; 95\% $\mathrm{Cl} 1.41-2.56$ ) and consistent among symptomatic (adjusted OR 1.74; 95\% Cl 1.16-2.63) and asymptomatic (adjusted OR 1.75; $95 \% \mathrm{Cl}$ 1.16-2.63) patients with carotid artery stenosis, among patients treated between 2010 and 2015 (adjusted OR 2.21; 95\% $\mathrm{Cl} 1.45-3.38$ ), and among the subgroup of patients aged $\geq 66$ years (adjusted OR 1.53; 95\% $\mathrm{Cl} 1.05-2.24$ ) after adjusting for medication use.

CONCLUSIONS CAS is associated with a rare but higher risk of $\mathrm{ICH}$ relative to $\mathrm{CEA}$. Future research is needed to devise strategies that minimize the risk of this serious complication after carotid artery revascularization.

https://thejns.org/doi/abs/10.3171/2017.8.JNS171142

KEY WORDS carotid endarterectomy; stenting; carotid artery stenosis; intracranial hemorrhage; hyperperfusion syndrome; vascular disorders

ABBREVIATIONS CAS = carotid artery stenting; CEA = carotid endarterectomy; ICD-10-CM = International Classification of Diseases, 10th Revision, Clinical Modification; $\mathrm{ICH}=$ intracranial hemorrhage; IPTW = inverse probability of treatment weighting.

SUBMITTED June 12, 2017. ACCEPTED August 2, 2017.

INCLUDE WHEN CITING Published online February 2, 2018; DOI: 10.3171/2017.8.JNS171142.

* M.A.H. and A.S.A. contributed equally to this work. 
$\mathrm{M}$ OST neurological complications after carotid artery revascularization are ischemic in nature. ${ }^{11}$ In a minority of patients, rapid correction of carotid artery stenosis can lead to a major increase in regional cerebral blood flow to areas of the brain with disrupted autoregulation after chronic ischemia. ${ }^{28}$ Cerebral hyperperfusion syndrome can result and manifest as ipsilateral headache, seizure, and focal neurological deficit due to cerebral edema or intracranial hemorrhage $(\mathrm{ICH}){ }^{28}$ Although ICH associated with cerebral hyperperfusion occurs in $<1 \%$ of patients who undergo carotid artery revascularization, it has devastating consequences in these patients; mortality rates of up to $50 \%$ and significant disability in the majority of survivors have been reported. $1,21,23,28$

Sparse data exist to determine whether the risk of ICH varies after different revascularization procedures. Although multiple randomized controlled trials have examined the relative safety and efficacy of carotid-revascularization procedures, they did not offer adequate power to examine rare complications such as $\mathrm{ICH}^{6,7,14}$ In the last decade, a few retrospective cohort studies examined this complication. ${ }^{21,23}$ The authors of those studies reported an increased risk of ICH after carotid artery stenting (CAS) relative to that after endarterectomy (CEA). ${ }^{21,23}$ However, there have been major advancements in CAS techniques and perioperative care, and the results of those studies might not apply to modern practice.

In this context, we conducted a population-based cohort study of patients who underwent CAS or CEA in the province of Ontario, Canada. The primary objective of our study was to examine the association between the incidence of ICH that occurred within 90 days after carotid artery intervention (90-day ICH) and CAS or CEA among patients with carotid artery stenosis. We also sought to establish the mortality rates of patients who had ICH after undergoing CEA or CAS.

\section{Methods Study Design}

We performed a retrospective cohort study of patients who underwent carotid artery revascularization for carotid artery stenosis. The databases used in this study are stored at the Institute for Clinical Evaluative Sciences, which is a prescribed entity under the Personal Health Information Privacy Act that houses and allows for usage of patient health information for research purposes without patient consent. The study was approved by the research ethics boards of St. Michael's Hospital and Sunnybrook Health Sciences Centre in Toronto, Ontario, Canada.

\section{Data Source}

We used administrative records for the population of Ontario over the period of April 1, 2002, to March 31, 2015. Health care services for Ontario's more than 13.5 million residents are universally accessible and funded by the provincial Ministry of Health and Long-Term Care. Population-based data sets that contain data on all emergency department visits, hospital admissions, inpatient and outpatient procedures, and physician billing claims in On- tario were used. These data sets are linked using a unique patient identifier to capture each patient's detailed clinical course. They have been validated for a variety of diagnoses and procedures, including carotid artery revascularization, and they are used routinely for epidemiological research $^{4,9,12,13,15,27}$ (see Supplemental Table 1 for a complete list and description of the databases used for this study).

\section{Identification of Exposure}

We captured data on all patients who underwent carotid artery revascularization between April 1, 2002, and March 1, 2015, by using Canadian Classification of Health Intervention procedure codes for CEA (1JE57Lx, extraction, carotid artery open approach) and CAS (1JE50x, dilation, carotid artery using percutaneous transluminal approach). These codes have been validated to accurately identify patients in our databases who were treated with CEA (positive predictive value 99\%; sensitivity 90\%) and those treated with CAS (positive predictive value $87 \%$; sensitivity 93\%). ${ }^{12}$ Patients $<40$ years old, those who underwent both CEA and CAS during the same admission, and those who underwent a combined carotid and coronary artery revascularization procedure were excluded.

\section{Outcome Measures}

The primary end point for this study was a new diagnosis of ICH within 90 days after CEA or CAS. We used International Classification of Diseases, 10th Revision, Clinical Modification (ICD-10-CM) diagnosis codes to identify patients who experienced ICH as a postprocedural complication during the index admission and those who were readmitted to a hospital with ICH within 90 days after the index procedure. We used the following ICD-10CM codes to define ICH: I60 (nontraumatic subarachnoid hemorrhage), I61 (nontraumatic intracerebral hemorrhage), and I62 (other nontraumatic ICH); these codes have been validated to accurately identify ICH in our databases. ${ }^{16,17}$ The definition of the primary outcome was limited to 90 days after carotid intervention, because previous studies found normalization of cerebral vasoreactivity and minimal risk of hyperperfusion syndrome in patients later than 90 days after carotid artery revascularization. ${ }^{2,25}$ Last, among patients with post-carotid artery revascularization $\mathrm{ICH}$, we also examined the 180-day mortality rate (measured from the ICH event date) as a secondary outcome.

\section{Covariates}

We measured the following patient-level covariates at baseline: age, sex, rural residence, neighborhood income quintile, Charlson Comorbidity Index, ${ }^{8}$ health services utilization (outpatient physician visits in the previous year, emergency department visits and hospital admissions in the previous 3 years), carotid artery symptom status (symptomatic or not), individual comorbid conditions, and previous revascularization procedures using validated coding algorithms (Supplemental Table 2). We used a 5-year look-back window before the index carotid procedure to establish comorbid conditions and previous revascularization procedures. Symptomatic carotid artery stenosis was defined as a hospital admission or emergency department 
TABLE 1. Baseline characteristics of study patients

\begin{tabular}{|c|c|c|c|c|}
\hline \multirow[b]{2}{*}{ Characteristic } & \multirow{2}{*}{$\begin{array}{l}\text { CEA Group } \\
(n=14,347)\end{array}$} & \multirow{2}{*}{$\begin{array}{l}\text { CAS Group } \\
(\mathrm{n}=2,341)\end{array}$} & \multicolumn{2}{|c|}{ SDiff* } \\
\hline & & & Unadjusted Comparison & After IPTW Adjustment \\
\hline \multicolumn{5}{|l|}{ Age in yrs } \\
\hline Mean \pm SD & $69.9 \pm 9.2$ & $70.0 \pm 10.8$ & 0.01 & 0.05 \\
\hline \multicolumn{5}{|l|}{ Range (no. [\%]) } \\
\hline$<70$ yrs & $6,547(45.6)$ & $1,030(44.0)$ & 0.03 & 0.08 \\
\hline$\geq 70$ yrs & $7,800(54.4)$ & $1,311(56.0)$ & 0.03 & 0.08 \\
\hline Female sex (no. [\%]) & $4,838(33.7)$ & 778 (33.2) & 0.01 & 0.01 \\
\hline Rural residence (no. [\%])† & $2,856(19.9)$ & $277(11.8)$ & 0.22 & 0.07 \\
\hline \multicolumn{5}{|l|}{ Neighborhood income quintile (no. [\%])† } \\
\hline 1 (lowest) & $2,997(20.9)$ & $394(16.8)$ & 0.10 & 0.00 \\
\hline 2 & $3,111(21.7)$ & $503(21.5)$ & 0.00 & 0.02 \\
\hline 3 & $2,875(20.0)$ & $476(20.3)$ & 0.01 & 0.01 \\
\hline 4 & $2,722(19.0)$ & $480(20.5)$ & 0.04 & 0.00 \\
\hline 5 (highest) & $2,586(18.0)$ & $479(20.5)$ & 0.06 & 0.01 \\
\hline \multicolumn{5}{|l|}{ Charlson Comorbidity Index (no. [\%])† } \\
\hline 0 & $3,956(27.6)$ & $532(22.7)$ & 0.11 & 0.02 \\
\hline 1 & $3,152(22.0)$ & $499(21.3)$ & 0.02 & 0.01 \\
\hline$\geq 2$ & $4,254(29.7)$ & $903(38.6)$ & 0.19 & 0.05 \\
\hline \multicolumn{5}{|l|}{ Health service utilization } \\
\hline Outpatient physician visits in past yr (mean \pm SD) & $14.6 \pm 8.6$ & $15.1 \pm 9.7$ & 0.05 & 0.01 \\
\hline ED visits in past 3 yrs (mean \pm SD) & $2.6 \pm 3.6$ & $3.2 \pm 3.4$ & 0.15 & 0.01 \\
\hline Hospital admissions in past 3 yrs (mean \pm SD) & $1.9 \pm 1.3$ & $2.2 \pm 1.5$ & 0.21 & 0.03 \\
\hline \multicolumn{5}{|l|}{ Comorbid conditions (no. [\%]) } \\
\hline Symptomatic carotid stenosis & $5,962(41.6)$ & $1,271(54.3)$ & 0.26 & 0.08 \\
\hline Coronary artery disease & $3,044(21.2)$ & $632(27.0)$ & 0.14 & 0.02 \\
\hline Acute myocardial infarction & $768(5.4)$ & $176(7.5)$ & 0.09 & 0.01 \\
\hline Congestive heart failure & $510(3.6)$ & $174(7.4)$ & 0.17 & 0.02 \\
\hline Peripheral arterial disease & $749(5.2)$ & $111(4.7)$ & 0.02 & 0.01 \\
\hline Diabetes mellitus & $4,839(34.0)$ & $880(37.6)$ & 0.07 & 0.02 \\
\hline Hypertension & $11,844(82.6)$ & $1,879(80.3)$ & 0.06 & 0.03 \\
\hline COPD & $4,231(29.4)$ & $690(29.5)$ & 0.00 & 0.05 \\
\hline Chronic kidney disease & $413(2.9)$ & $109(4.7)$ & 0.09 & 0.02 \\
\hline \multicolumn{5}{|l|}{ Previous procedures (no. [\%]) } \\
\hline Carotid endarterectomy & $536(3.7)$ & $70(3.0)$ & 0.04 & 0.03 \\
\hline Coronary revascularization & $248(1.7)$ & $27(1.2)$ & 0.05 & 0.02 \\
\hline Peripheral revascularization & $426(3.0)$ & $89(3.8)$ & 0.05 & 0.02 \\
\hline \multicolumn{5}{|l|}{ Procedure \& institution characteristics (no. [\%]) } \\
\hline \multicolumn{5}{|l|}{ Yr of procedure $\neq$} \\
\hline 2002-2006 & $5,647(39.4)$ & $746(31.9)$ & 0.16 & 0.01 \\
\hline $2007-2010$ & $4,436(30.9)$ & $740(31.6)$ & 0.02 & 0.02 \\
\hline 2011-2015 & $4,264(29.7)$ & $855(36.5)$ & 0.14 & 0.03 \\
\hline Urgent admission & $2,488(17.3)$ & $1,118(47.8)$ & 0.69 & 0.01 \\
\hline Stroke center & $10,415(72.6)$ & $2,040(87.1)$ & 0.37 & 0.02 \\
\hline \multicolumn{5}{|l|}{ Medication use (no. [\%])§ } \\
\hline Any antiplatelet agent & $4,965(49.9)$ & $996(61.7)$ & 0.24 & 0.03 \\
\hline Acetylsalicylic acid & $2,672(26.8)$ & $436(27.0)$ & 0.00 & 0.01 \\
\hline Dipyridamole & $1,200(12.1)$ & $212(13.1)$ & 0.03 & 0.02 \\
\hline Clopidogrel & $2,815(28.3)$ & $766(47.5)$ & 0.40 & 0.01 \\
\hline Statin & $7,852(78.9)$ & $1,241(76.9)$ & 0.05 & 0.03 \\
\hline
\end{tabular}


》 CONTINUED FROM PAGE 1524

TABLE 1. Baseline characteristics of study patients

\begin{tabular}{|c|c|c|c|c|}
\hline \multirow[b]{2}{*}{ Characteristic } & \multirow{2}{*}{$\begin{array}{l}\text { CEA Group } \\
(n=14,347)\end{array}$} & \multirow{2}{*}{$\begin{array}{l}\text { CAS Group } \\
(n=2,341)\end{array}$} & \multicolumn{2}{|c|}{ SDiff* } \\
\hline & & & Unadjusted Comparison & After IPTW Adjustment \\
\hline \multicolumn{5}{|l|}{ Medication use (no. [\%])§ (continued) } \\
\hline ACE inhibitor or ARB & $6,904(69.4)$ & $1,138(70.5)$ & 0.02 & 0.03 \\
\hline Beta-blocker & $4,223(42.4)$ & $715(44.3)$ & 0.04 & 0.00 \\
\hline Diuretic & $4,003(40.2)$ & $698(43.2)$ & 0.06 & 0.05 \\
\hline Calcium channel blocker & $4,170(41.9)$ & $667(41.3)$ & 0.01 & 0.04 \\
\hline Oral antidiabetic & $2,153(21.6)$ & $394(24.4)$ & 0.07 & 0.01 \\
\hline Insulin & $592(5.9)$ & $147(9.1)$ & 0.12 & 0.02 \\
\hline Warfarin & $861(8.7)$ & $211(13.1)$ & 0.14 & 0.00 \\
\hline NOAC & $114(1.1)$ & $30(1.9)$ & 0.06 & 0.02 \\
\hline
\end{tabular}

$\mathrm{ACE}$ = angiotensin-converting enzyme; $\mathrm{ARB}$ = angiotensin II receptor blocker; $\mathrm{COPD}=$ chronic obstructive pulmonary disease; $\mathrm{ED}=$ emergency department; $\mathrm{IQR}=$ interquartile range; $\mathrm{NOAC}=$ novel oral anticoagulant; $\mathrm{SDiff}=$ standardized difference .

* An SDiff of $>0.1$ indicates significant difference.

† Missing values: 6 rural residence (0.04\%); 65 neighborhood income quintile (0.4\%); 3392 Charlson Comorbidity Index (20.3\%).

‡ For year 2002, only procedures performed after March 31, 2002, were included. For year 2015, procedures performed after March 1, 2015, were not included.

$\S$ Reported for only those patients aged $\geq 66$ years (9952 [69.4\%] CEA, 1614 [68.9\%] CSA).

visit within the previous 6 months for ischemic stroke or transient ischemic attack. Furthermore, we used the Ontario Drug Benefit Claims database to establish baseline medication use among patients aged $\geq 66$ years. This database captures information on medication prescriptions filled by people in Ontario aged $\geq 65$ years or those who receive social assistance. Therefore, we determined baseline medication use for those aged $\geq 66$ years by evaluating medication prescriptions filled within 1 year before the index procedure. These covariates were chosen because results of previous studies suggested that they are potential risk factors for cerebral hyperperfusion syndrome and ICH after carotid artery revascularization..$^{18,21,22,28}$ Hence, they might confound the relationship between carotid-revascularization procedure type and ICH risk. In addition, we captured year of procedure (2002-2006, 2007-2010, or 2011-2015), type of procedure (urgent or elective), and type of center (stroke center or non-stroke center) as procedural and institutional factors.

\section{Statistical Analysis}

We calculated standardized differences to compare baseline characteristics between those who underwent CEA and those who underwent CAS. ${ }^{20,29}$ Standardized differences represent the mean difference as a percentage of the standard deviation. ${ }^{29}$ The advantage of standardized differences over traditional significance testing is that they are not as sensitive to sample size, which provides a sense of the relative magnitude of differences. ${ }^{20}$ Standardized differences greater than 0.1 were considered meaningful. ${ }^{20}$

We first calculated unadjusted ORs for the risk of primary and secondary outcomes according to carotid-revascularization strategy using simple logistic regression analysis. We then used propensity score methods to account for the risk of confounding that results from differences in baseline characteristics of CEA- and CAS-treated patients. We constructed a multivariable logistic regression model to calculate propensity scores using all the covariates listed in Table 1 except for medication use, because data for this covariate were available only for patients aged $\geq 66$ years. Then, we used inverse probability of treatment weighting (IPTW) based on the propensity scores to adjust for baseline differences between the 2 groups. ${ }^{3,19} \mathrm{We}$ formally examined the balance of baseline characteristics between the IPTW-adjusted cohorts by calculating standardized differences after IPTW adjustment using the approach described by Austin and Stuart. ${ }^{5}$ We then calculated adjusted ORs for the risk of primary and secondary outcomes according to carotid-revascularization strategy using IPTW-adjusted logistic regression models.

We also conducted several sensitivity analyses to ensure that our findings were robust and reproducible. Hemorrhagic conversion of ischemic stroke might have a pathophysiology different from that of ICH caused by hyperperfusion syndrome. To examine the effect of this potential bias, we repeated our analyses after excluding patients who had postprocedural ischemic stroke. Postprocedural ischemic stroke was determined using validated ICD-10-CM diagnosis codes (I63 [excluding I63.6], I64, and H34.1), if it was reported within 90 days after the carotid-revascularization procedure. ${ }^{17}$ Second, we examined the ICH rates among the subgroups of patients with symptomatic or asymptomatic presentation of carotid artery stenosis separately, because they might have difference baseline risks for hyperperfusion syndrome and ICH. ${ }^{28}$ Third, we repeated our analysis for patients who underwent carotid artery revascularization between 2010 and 2015 to reflect more contemporary practice after publication of the large multicenter Carotid Revascularization Endarterectomy versus Stenting Trial (CREST) in 2010. ${ }^{6}$ Last, because differences in antiplatelet or anticoagulant use might bias the results, we repeated our primary analysis in the cohort of patients aged $\geq 66$ years and included baseline medication use as a covariate in our IPTW-adjusted models. This analysis allowed us to adjust our models for medications that might 
TABLE 2. Outcomes after carotid artery revascularization in the overall cohort

\begin{tabular}{|c|c|c|c|c|c|c|}
\hline Outcome or Subgroup & $\begin{array}{l}\text { CEA Group }(n=14,347) \\
\text { (No./Total }[\%])\end{array}$ & $\begin{array}{l}\text { CAS Group }(\mathrm{n}=2,341) \\
\text { (No./Total }[\%])\end{array}$ & $\begin{array}{l}\text { Unadjusted OR } \\
\text { for CAS }(95 \% \mathrm{Cl})\end{array}$ & $\begin{array}{c}\mathrm{p} \\
\text { Value }\end{array}$ & $\begin{array}{l}\text { Adjusted OR for } \\
\text { CAS }(95 \% \mathrm{Cl})^{*}\end{array}$ & $\begin{array}{c}\mathrm{p} \\
\text { Value }\end{array}$ \\
\hline Primary outcome: 90-day ICH & $60(0.42)$ & $20(0.85)$ & $2.05(1.24-3.41)$ & 0.006 & $1.77(1.32-2.36)$ & $<0.001$ \\
\hline $\begin{array}{l}\text { Secondary outcome: } 180 \text {-day death } \\
\text { after } 90 \text {-day ICH }\end{array}$ & $26 / 60(43.3)$ & $8 / 20(40.0)$ & $0.87(0.31-2.44)$ & 0.79 & $0.52(0.28-0.96)$ & 0.036 \\
\hline \multicolumn{7}{|l|}{ Subgroup analyses } \\
\hline $\begin{array}{l}\text { 90-day } \mathrm{ICH} \text { excluding those w/ post- } \\
\text { procedural ischemic stroke } †\end{array}$ & $55 / 14,194(0.39)$ & $19 / 2,277(0.83)$ & $2.16(1.28-3.65)$ & 0.004 & $1.90(1.41-2.56)$ & $<0.001$ \\
\hline 90-day ICH in symptomatic patients & $28 / 5,962(0.47)$ & $8 / 1,271(0.63)$ & $1.34(0.61-2.95)$ & 0.46 & $1.74(1.16-2.63)$ & 0.008 \\
\hline 90-day ICH in asymptomatic patients & $32 / 8,385(0.38)$ & $12 / 1,070(1.1)$ & $2.96(1.52-5.77)$ & 0.001 & $1.75(1.16-2.63)$ & 0.008 \\
\hline 90-day ICH in post-CREST cohortł & $25 / 5,333(0.47)$ & $9 / 1,014(0.89)$ & $1.90(0.89-4.09)$ & 0.10 & $2.21(1.45-3.38)$ & $<0.001$ \\
\hline
\end{tabular}

confound the relationship between carotid-revascularization strategy and $\mathrm{ICH}$, such as antiplatelet agents, warfarin, and novel oral anticoagulants.

All of the statistical analyses were performed using SAS Enterprise Guide 7.1 (SAS Institute). Statistical significance was defined by a 2 -tailed $\mathrm{p}$ value $<0.05$.

\section{Results \\ Patient Cohort}

A total of 16,688 patients were included; $86 \%$ underwent CEA, and $14 \%$ underwent CAS. Table 1 lists baseline characteristics of the study patients. The mean $( \pm$ SD) ages of the 2 groups were similar (CEA group 70 [9.2] years, CAS group 70 [10.8] years). Approximately one-third of the patients in each group were female. Before adjustment, CAS-treated patients were more likely to have an urban residence and a higher overall comorbidity burden, as indicated by a Charlson Comorbidity Index of $\geq 2$. CAStreated patients also were more likely than CEA-treated patients to have symptomatic carotid artery stenosis (54\% vs $42 \%$, respectively), coronary artery disease, and congestive heart failure and to use more health services in the form of emergency department visits or hospital admissions within the past 3 years before carotid artery revascularization. In addition, CAS-treated patients were more likely to have an urgent admission, be treated at a stroke center, and have the procedure later in the study period between 2011 and 2015. With respect to medication use among those aged $\geq 66$ years, CAS-treated patients were more likely than CEA-treated patients to be on an antiplatelet agent (62\% vs $50 \%$, respectively), insulin therapy (9\% vs $6 \%$, respectively), or warfarin (13\% vs $9 \%$, respectively). After IPTW adjustment, all baseline covariates between the 2 groups were well balanced, as indicated by standardized differences of $\leq 0.1$ (Table 1 ).

\section{Outcomes}

A total of $80(0.48 \%)$ patients experienced ICH within 90 days after carotid artery revascularization. After IPTW adjustment, the risk for the primary outcome was signifi- cantly higher after CAS $(0.85 \%)$ than after CEA $(0.42 \%)$ (adjusted OR 1.77; 95\% CI 1.32-2.36). The 180-day mortality rate in the overall cohort was $2.7 \%(n=450)$, whereas the 180-day mortality rate among patients who suffered ICH was $42.5 \%(\mathrm{n}=34)(40 \%$ for CAS-treated patients, $43.3 \%$ for CEA-treated patients). See Table 2 for the primary and secondary outcomes in the overall study cohort.

\section{Subgroup and Sensitivity Analyses}

We conducted several subgroup and sensitivity analyses to ensure that our results were robust and reproducible (Tables 2 and 3). First, CAS-treated patients had a higher risk of ICH (adjusted OR 1.90; 95\% CI 1.41-2.56) than CEA-treated patients after we excluded patients who developed postprocedural ischemic stroke. Second, our results in the symptomatic (adjusted OR for ICH among CAS-treated patients vs CEA-treated patients $1.74 ; 95 \%$ CI 1.16-2.63) and asymptomatic (adjusted OR 1.75; 95\% CI 1.16-2.63) subgroups were consistent. Third, we found that the risk for ICH was consistently higher after CAS among a contemporary cohort of patients who underwent carotid artery revascularization exclusively in the postCREST era (adjusted OR 2.21; 95\% CI 1.45-3.38). Last, our analyses in the cohort of patients aged $\geq 66$ years confirmed that CAS-treated patients experienced a higher rate of ICH (adjusted OR 1.53; 95\% CI 1.05-2.24) than did CEA-treated patients despite further adjustment for baseline medication use in our models, which included antiplatelet agents, warfarin, and novel oral anticoagulants (Table 3).

\section{Discussion}

In this contemporary population-based cohort, we found a higher risk of postoperative ICH among the recipients of CAS relative to recipients of CEA. Our findings were consistent after adjustment for baseline characteristics and multiple potential confounders and across different patient subgroups and sensitivity analyses. However, the overall risk of ICH was quite low $(<1 \%)$ regardless of 
TABLE 3. Sensitivity analysis of outcomes after carotid revascularization in cohort of patients aged $\geq 66$ years

\begin{tabular}{ccccccc}
\hline $\begin{array}{c}\text { Primary } \\
\text { Outcome }\end{array}$ & $\begin{array}{c}\text { CEA Group }(n=9952) \\
(\text { No. }[\%])\end{array}$ & $\begin{array}{c}\text { CAS Group }(n=1614) \\
(\text { No. }[\%])\end{array}$ & $\begin{array}{c}\text { Unadjusted OR for CAS Group } \\
(95 \% \mathrm{Cl})\end{array}$ & $\begin{array}{c}p \\
\text { Value }\end{array}$ & $\begin{array}{c}\text { Adjusted OR for CAS Group } \\
(95 \% \text { Cl })^{*}\end{array}$ & $\begin{array}{c}p \\
\text { Value }\end{array}$ \\
\hline 90-day ICH & $38(0.38)$ & $11(0.68)$ & $1.79(0.91-3.51)$ & 0.090 & $1.53(1.05-2.24)$ & 0.027 \\
\hline
\end{tabular}

* Odds were adjusted based on IPTW using propensity scores calculated from all variables listed in Table 1, including medication use.

the carotid-revascularization strategy used; therefore, the difference in ICH rates observed between patients who underwent CAS and those who underwent CEA might not be clinically significant. Although this complication was rare, we found that it had a substantial mortality rate of more than $40 \%$; this rate was slightly higher in the CEA group (43\%) than in the CAS group (40\%).

The underlying mechanism of this discrepancy in ICH risk remains unclear. Our results suggest that this association is independent of preoperative antiplatelet or anticoagulant use and symptomatic or asymptomatic presentation of carotid artery stenosis. Potential mechanisms include differences in the risk and time course of hyperperfusion syndrome between CAS- and CEA-treated patients. As reported by Park et al., ${ }^{24}$ stent deployment to the carotid bulb body uniquely stuns the baroreceptors and is associated with substantial increase in the risk of hyperperfusion syndrome. Ogasawara et al. ${ }^{23}$ found that hyperperfusion occurs typically within the first 12 hours after CAS, whereas in patients who have undergone CEA, it peaks on the 6th postoperative day. Differences in perioperative structure and process of care for CAS and CEA recipients might also contribute to the difference in ICH risk. ${ }^{21}$

Although multiple randomized controlled trials examined the relative efficacy of carotid-revascularization procedures, they have not offered adequate power to examine rare complications such as ICH. ${ }^{6,710}$ The few observational studies of comparative ICH risk after different carotidrevascularization procedures offered conflicting findings. In contrast to us, Ogasawara et al. ${ }^{23}$ found similar rates of ICH between CAS- and CEA-treated patients, whereas McDonald et al. ${ }^{21}$ and Timaran et al. ${ }^{26}$ found risk of ICH and ICH-related death to be higher after CAS than after CEA. However, previous studies suffered from several limitations, including using older cohorts that did not reflect modern CAS technology and practice, small sample sizes, limited data on follow-up to in-hospital events, a lack of or inadequate adjustment for multiple important confounders (e.g., patient medication use and health services utilization), and selection bias. ${ }^{21,23,26}$

The strengths of our study include our use of a contemporary population-based sample that reflects modern practice, inclusion of long-term follow-up data, and adjustment for multiple important confounders. However, our results should be interpreted with caution. Our findings are limited mainly by the nature of the administrative database, which does not include information about all potential confounders. For example, our data-capture process retrieved only prescription medications filled; therefore, the use of over-the-counter medications, such as aspirin, might have been underreported in our study. Furthermore, we lacked information about antiplatelet and anticoagulant use among patients aged 65 years or younger. However, this subgroup of patients represents less than one-third of our cohort. Furthermore, a subgroup analysis of patients aged 66 years or older, for whom medication-use data were available, resulted in findings consistent with those of the primary analysis. In addition, our databases did not contain data on postoperative blood pressure control; this lack of data is another potential source of cofounding, because hyperperfusion syndrome and ICH are associated with systemic hypertension after carotid artery revascularization. However, all patients in Ontario who undergo carotid artery revascularization generally also undergo 24 hours of close monitoring of blood pressure and neurological status in an intensive care unit setting regardless of whether they undergo CEA or CAS. Furthermore, data regarding potential predictors, such as severity of carotid artery stenosis, contralateral carotid artery stenosis/occlusion, plaque characteristics, carotid artery and aortic arch anatomy, hostile neck features (such as previous radical neck surgery, external beam radiotherapy, contralateral laryngeal nerve palsy, or tracheostomy), and other procedural factors, were not available and might have been imbalanced between the 2 comparator groups. In addition, information on postprocedure use of medications, such as dual antiplatelet therapy, was not captured and was almost certainly higher in the CAS group than in the CEA group, which potentially accounts for some of the excess bleeds. Last, we were not able to obtain information on the functional outcomes of patients who experienced a neurological event.

Future studies should investigate potential mechanisms for this discrepancy in ICH risk and identify the optimal strategies for mitigating this risk in the perioperative period among CAS-treated patients. Meanwhile, healthcare providers caring for patients with carotid artery stenosis should be mindful of this rare but devastating complication associated with carotid artery revascularization.

\section{Conclusions}

CAS is associated with a rare but higher risk of ICH than CEA. This association seems to be independent of baseline antiplatelet or anticoagulant use and symptomatic or asymptomatic presentation of carotid artery stenosis. Future research is needed to devise strategies that minimize the risk of this serious complication after carotid artery revascularization.

\section{Acknowledgments}

We thank Jiming Fang, PhD, and Huiting Ma, MSc, from the Institute for Clinical Evaluative Sciences (Toronto, Ontario, Canada) for their assistance with data-set creation and management. 


\section{References}

1. Abou-Chebl A, Yadav JS, Reginelli JP, Bajzer C, Bhatt D, Krieger DW: Intracranial hemorrhage and hyperperfusion syndrome following carotid artery stenting: risk factors, prevention, and treatment. J Am Coll Cardiol 43:1596-1601, 2004

2. Ascher E, Markevich N, Schutzer RW, Kallakuri S, Jacob T, Hingorani AP: Cerebral hyperperfusion syndrome after carotid endarterectomy: predictive factors and hemodynamic changes. J Vasc Surg 37:769-777, 2003

3. Austin PC: The performance of different propensity-score methods for estimating differences in proportions (risk differences or absolute risk reductions) in observational studies. Stat Med 29:2137-2148, 2010

4. Austin PC, Daly PA, Tu JV: A multicenter study of the coding accuracy of hospital discharge administrative data for patients admitted to cardiac care units in Ontario. Am Heart J 144:290-296, 2002

5. Austin PC, Stuart EA: Moving towards best practice when using inverse probability of treatment weighting (IPTW) using the propensity score to estimate causal treatment effects in observational studies. Stat Med 34:3661-3679, 2015

6. Brott TG, Hobson RW II, Howard G, Roubin GS, Clark WM, Brooks W, et al: Stenting versus endarterectomy for treatment of carotid-artery stenosis. N Engl J Med 363:11-23, 2010

7. Brott TG, Howard G, Roubin GS, Meschia JF, Mackey A, Brooks W, et al: Long-term results of stenting versus endarterectomy for carotid-artery stenosis. N Engl J Med 374:1021-1031, 2016

8. Charlson ME, Pompei P, Ales KL, MacKenzie CR: A new method of classifying prognostic comorbidity in longitudinal studies: development and validation. J Chronic Dis 40:373383, 1987

9. Gershon AS, Wang C, Guan J, Vasilevska-Ristovska J, Cicutto L, To T: Identifying individuals with physician diagnosed COPD in health administrative databases. COPD 6:388-394, 2009

10. Gurm HS, Yadav JS, Fayad P, Katzen BT, Mishkel GJ, Bajwa TK, et al: Long-term results of carotid stenting versus endarterectomy in high-risk patients. N Engl J Med 358:15721579,2008

11. Hosoda K, Kawaguchi T, Shibata Y, Kamei M, Kidoguchi K, Koyama J, et al: Cerebral vasoreactivity and internal carotid artery flow help to identify patients at risk for hyperperfusion after carotid endarterectomy. Stroke 32:1567-1573, 2001

12. Hussain MA, Mamdani M, Saposnik G, Tu JV, Turkel-Parrella $\mathrm{D}$, Spears J, et al: Validation of carotid artery revascularization coding in Ontario health administrative databases. Clin Invest Med 39:E73-E78, 2016

13. Hussain MA, Mamdani M, Tu JV, Saposnik G, Khoushhal Z, Aljabri B, et al: Impact of clinical trial results on the temporal trends of carotid endarterectomy and stenting from 2002 to 2014. Stroke 47:2923-2930, 2016

14. Hussain MA, Verma S, Gupta N, Al-Omran M: Carotid artery revascularization: what's the best strategy? Circulation 131:2226-2231, 2015

15. Hux JE, Ivis F, Flintoft V, Bica A: Diabetes in Ontario: determination of prevalence and incidence using a validated administrative data algorithm. Diabetes Care 25:512-516, 2002

16. Juurlink D, Preyra C, Croxford R, Chong A, Austin P, Tu J, et al: Canadian Institute for Health Information Discharge Abstract Database: A Validation Study. Toronto: Institute for Clinical Evaluative Sciences, 2006

17. Kokotailo RA, Hill MD: Coding of stroke and stroke risk factors using international classification of diseases, revisions 9 and 10. Stroke 36:1776-1781, 2005

18. Lieb M, Shah U, Hines GL: Cerebral hyperperfusion syn- drome after carotid intervention: a review. Cardiol Rev 20:84-89, 2012

19. Lunceford JK, Davidian M: Stratification and weighting via the propensity score in estimation of causal treatment effects: a comparative study. Stat Med 23:2937-2960, 2004

20. Mamdani M, Sykora K, Li P, Normand SL, Streiner DL, Austin PC, et al: Reader's guide to critical appraisal of cohort studies: 2. Assessing potential for confounding. BMJ 330:960-962, 2005

21. McDonald RJ, Cloft HJ, Kallmes DF: Intracranial hemorrhage is much more common after carotid stenting than after endarterectomy: evidence from the National Inpatient Sample. Stroke 42:2782-2787, 2011

22. Moulakakis KG, Mylonas SN, Sfyroeras GS, Andrikopoulos $\mathrm{V}$ : Hyperperfusion syndrome after carotid revascularization. J Vasc Surg 49:1060-1068, 2009

23. Ogasawara K, Sakai N, Kuroiwa T, Hosoda K, Iihara K, Toyoda K, et al: Intracranial hemorrhage associated with cerebral hyperperfusion syndrome following carotid endarterectomy and carotid artery stenting: retrospective review of 4494 patients. J Neurosurg 107:1130-1136, 2007

24. Park ST, Kim JK, Yoon KH, Park SO, Park SW, Kim JS, et al: Atherosclerotic carotid stenoses of apical versus body lesions in high-risk carotid stenting patients. AJNR Am J Neuroradiol 31:1106-1112, 2010

25. Russell D, Dybevold S, Kjartansson O, Nyberg-Hansen R, Rootwelt K, Wiberg J: Cerebral vasoreactivity and blood flow before and 3 months after carotid endarterectomy. Stroke 21:1029-1032, 1990

26. Timaran CH, Veith FJ, Rosero EB, Modrall JG, Valentine RJ, Clagett GP: Intracranial hemorrhage after carotid endarterectomy and carotid stenting in the United States in 2005. J Vasc Surg 49:623-629, 2009

27. Tu K, Chen Z, Lipscombe LL: Prevalence and incidence of hypertension from 1995 to 2005: a population-based study. CMAJ 178:1429-1435, 2008

28. van Mook WN, Rennenberg RJ, Schurink GW, van Oostenbrugge RJ, Mess WH, Hofman PA, et al: Cerebral hyperperfusion syndrome. Lancet Neurol 4:877-888, 2005

29. Yang D, Dalton JE: A unified approach to measuring the effect size between two groups using SAS, presented at the SAS Global Forum, 2012 (http://support.sas.com/resources/ papers/proceedings12/335-2012.pdf) [Accessed October 12, 2017]

\section{Disclosures}

Dr. Bhatt reports that he is on the advisory board of Cardax, Elsevier Practice Update Cardiology, Medscape Cardiology, and Regado Biosciences; is on the board of directors for the Boston VA Research Institute and Society of Cardiovascular Patient Care; is a chair on the American Heart Association Quality Oversight Committee; is on the Data Monitoring Committee for the Cleveland Clinic, Duke Clinical Research Institute, Harvard Clinical Research Institute, Mayo Clinic, and Population Health Research Institute; has received honoraria from the American College of Cardiology (senior associate editor, Clinical Trials and News, ACC.org), Belvoir Publications (editor-in-chief, Harvard Heart Letter), Duke Clinical Research Institute (clinical trial steering committees), Harvard Clinical Research Institute (clinical trial steering committee), HMP Communications (editor-in-chief, Journal of Invasive Cardiology), Journal of the American College of Cardiology (guest editor and associate editor), Population Health Research Institute (clinical trial steering committee), Slack Publications (chief medical editor, Cardiology Today's Intervention), Society of Cardiovascular Patient Care (secretary/treasurer), and WebMD (CME steering committees); is deputy editor of Clinical Cardiology; is a chair on the NCDR-ACTION Registry Steering Committee and the VA CART Research and Publica- 
tions Committee; has received research funding from Amarin, Amgen, AstraZeneca, Bristol-Myers Squibb, Chiesi, Eisai, Ethicon, Forest Laboratories, Ironwood, Ischemix, Lilly, Medtronic, Pfizer, Roche, Sanofi Aventis, and The Medicines Company; has received royalties from Elsevier (editor, Cardiovascular Intervention: A Companion to Braunwald's Heart Disease); is site coinvestigator for Biotronik, Boston Scientific, and St. Jude Medi$\mathrm{cal}$; is a trustee for the American College of Cardiology; and has performed unfunded research for FlowCo, Merck, PLx Pharma, and Takeda. This study was funded by the Physicians' Services, Inc., Foundation and the King Saud University-Li Ka Shing Collaborative Research Program. This study was supported also by the Institute for Clinical Evaluative Sciences (ICES), which is funded by an annual grant from the Ontario Ministry of Health and Long-Term Care (MOHLTC). Dr. Saposnik is supported by the Heart and Stroke Foundation Career Award following an open peer-reviewed competition. The opinions, results, and conclusions reported in this paper are those of the authors and are independent from the funding sources. No endorsement by the ICES or the Ontario MOHLTC is intended or should be inferred. All data sets used in this study were linked using unique encoded identifiers and analyzed at the ICES. Parts of this material are based on data and information compiled and provided by the Canadian Institute for Health Information (CIHI). However, the analyses, conclusions, opinions, and statements expressed herein are those of the authors, and not necessarily those of the CIHI.

\section{Author Contributions}

Conception and design: all authors. Analysis and interpretation of data: Al-Omran, Hussain, Alali, Mamdani, Salata, De Mestral. Drafting the article: Hussain, Alali. Critically revising the article: all authors. Reviewed submitted version of manuscript: all authors. Approved the final version of the manuscript on behalf of all authors: Al-Omran. Statistical analysis: Hussain. Administrative/technical/material support: Al-Omran. Study supervision: Al-Omran.

\section{Supplemental Information}

Online-Only Content

Supplemental material is available with the online version of the article.

Supplemental Tables 1 and 2. https://thejns.org/doi/suppl/ 10.3171/2017.8.JNS171142.

\section{Previous Presentations}

This study was presented at the 39th Annual Meeting of the Canadian Society for Vascular Surgery, Banff, Alberta, Canada, September 15-16, 2017.

\section{Current Affiliations}

Dr. Alali: Department of Neurological Surgery, University of Washington, Seattle, WA.

\section{Correspondence}

Mohammed Al-Omran: St. Michael's Hospital, Toronto, ON, Canada.alomranm@smh.ca. 